\title{
I. CORE-DISCING AND OTHER DRILLING EFFECTS IN DSDP LEG 42A MEDITERRANEAN SEDIMENT CORES
}

\author{
Robert B. Kidd, Institute of Oceanographic Sciences, Wormley, Surrey, United Kingdom
}

\section{INTRODUCTION}

Since deep-sea drilling began in Autumn 1968, the Deep Sea Drilling Project staff scientists and technicians, together with the continually changing scientific teams aboard Glomar Challenger have learned by experience to identify artifacts in the recovered sediments and rocks that were caused by the coring process. Most of these are immediately recognizable as drilling-induced features, but a number are subtle and are very similar to certain sedimentary structures. The analysis of sedimentary structures is recognized as a powerful tool when used by geologists for paleoenvironmental interpretation. Unfortunately there has been no attempt to catalogue all new occurrences of supposed drilling artifacts as they were encountered during the life of DSDP. This lack of suitable reference material has sometimes resulted in misidentification of structural features and their erroneous use as part of a paleoenvironmental interpretation for the sediments under study.

A number of the more subtle drilling artifacts were encountered during Leg $42 \mathrm{~A}$ and indeed some were, at first, misidentified. The purpose of this appendix is to set apart from the main text illustrations of some problematical structures and to explain our interpretation of them. This is done to ensure that readers scanning the core photographs in the site chapters and others who may encounter such features on subsequent cruises are aware of these interpretations. The scope of this contribution, however, does not include discussion of the technical aspects of the drilling process and equipment which cause the artifacts. A review of the whole range of disturbance features encountered over the seven years of the Deep Sea Drilling Project is being assembled (Kidd and Thompson, in preparation), and this will discuss some of these technical aspects.

\section{GENERAL REMARKS ON CORE DISTURBANCE IN LEG 42A CORES}

As on most other DSDP cruises, each core recovered on Leg 42A was logged for core disturbance effects as well as for other visual features (see Explanatory Notes, this volume). Table 1 is a compilation of the data on core disturbance for each site and identifies the levels at which the major changes in recovery took place.

Core disturbance characteristics are controlled both by the nature of the sediment prior to drilling and by the drilling process itself. Whether a sediment is soft, stiff, or lithified prior to penetration of the drillbit depends on its degree of compaction and lithification and these, in turn, are a function of a wide range of interrelated factors, including, for example, the geological setting of the site, thickness of overburden, sediment composition, and age. The type of recovery obtained is the result of the drillbit chosen, the drilling rate, and weight on the bit, the levels of washing, and the time available for penetration of the lithologic unit in question. All of these are under the control of the team on the rig floor but, within the limitations of the equipment being used, their operations are, of course, strongly influenced by the type of sediment being penetrated.

Table 1 shows for the Leg 42A holes that, although the lithologies penetrated in each hole were fairly similar (mostly marls and marlstones, except for the Messinian evaporite formation), there is little similarity site to site in the levels at which the sediments became stiff or lithified due to the factors outlined above. (This is to be expected from the wide differences in site location.) More importantly, the table shows clearly that core disturbance is only imperfectly correlated with changes in the sediment itself. One might expect the first undisturbed sediment downhole would occur where the sediments became fairly stiff and similarly the last occurrence of disturbed sediment would occur where they became completely lithified. Rarely are these generalizations true: the type of recovery invariably hinges on characteristics of the coring program itself and on the limitations imposed by the drilling equipment.

\section{SPECIAL DISTURBANCE FEATURES ENCOUNTERED IN LEG 42A CORES}

\section{Core Discing}

When 1.5-meter sections of sediment core are split longitudinally in the Glomar Challenger's laboratory, those that are partially or completely lithified frequently are found to be broken horizontally into pieces. At the breaks, the upcore surfaces of the pieces are convex while the undersurface of those above are concave. This is the result of the individual pieces rotating upon one another inside the core barrel as the core is being cut. Often, the break is along a change in lithology such as a sandy horizon or a silt or shell lamina, although just as frequently no lithological change is apparent.

Figure 1 shows examples of this rotation within the core barrel that were found in cores from Leg 42A. 
TABLE 1

Levels of Changes in Core Disturbance in Leg 42A Drill Holes (m)

\begin{tabular}{|c|c|c|c|c|c|c|c|c|}
\hline & $\begin{array}{l}\text { Site } 371 \\
\text { South } \\
\text { Balearic } \\
\text { Basin }\end{array}$ & $\begin{array}{c}\text { Site } 372 \\
\text { Menorca Rise }\end{array}$ & $\begin{array}{c}\text { Site 373A } \\
\text { Tyrrhenian } \\
\text { Basin }\end{array}$ & $\begin{array}{l}\text { Site } 374 \\
\text { Ionian } \\
\text { Basin }\end{array}$ & $\begin{array}{l}\text { Site } 375 \\
\quad \text { Florence I }\end{array}$ & $\begin{array}{l}\text { Site } 376 \\
\text { ise }\end{array}$ & $\begin{array}{c}\text { Site } 377 \\
\text { Mediterranean } \\
\text { Ridge Cleft }\end{array}$ & $\begin{array}{c}\text { Site } 378 / 378 \mathrm{~A} \\
\text { Cretan Basin }\end{array}$ \\
\hline $\begin{array}{l}\text { Sediments } \\
\text { became } \\
\text { stiff }\end{array}$ & 361 & 131 & - & 295 & - & 36 & 249.5 & 84 \\
\hline $\begin{array}{l}\text { Sediments } \\
\text { became } \\
\text { lithified }\end{array}$ & 408 & 416 & - & 378 & 137.5 & 55 & 200 & 131 \\
\hline $\begin{array}{l}\text { Highest } \\
\text { undisturbed } \\
\text { sediment }\end{array}$ & 361 & 136 & 101 & 158 & 247 & 66 & 191 & 85 \\
\hline $\begin{array}{l}\text { Lowest } \\
\text { disturbed } \\
\text { sediment }\end{array}$ & 470 & 874 & 269 & 408 & 468 & 151 & 191 & 302 \\
\hline $\begin{array}{l}\text { Lowest } \\
\text { sediment } \\
\text { slurry }\end{array}$ & 1.5 & 874 & 269 & 384 & 464 & 151 & 191 & 174 \\
\hline $\begin{array}{l}\text { Terminal } \\
\text { depth }\end{array}$ & 551 & 885 & 457.5 & 457 & 821 & 216.5 & 263 & 343.5 \\
\hline Remarks & - & $\begin{array}{l}\text { Gypsum rocks } \\
\text { at }-150 \text { to }-200 \mathrm{~m} \\
\text { but unlithified } \\
\text { sediments below }\end{array}$ & $\begin{array}{l}\text { Basalt complex } \\
\text { begins } 270 \mathrm{~m}\end{array}$ & $\begin{array}{l}\text { Dolomite } \\
\text { begins at } \\
378 \mathrm{~m} \text {; } \\
\text { evaporites } \\
\text { below }\end{array}$ & $\begin{array}{l}\text { Gypsum begins } \\
\text { at } 137.5 \mathrm{~m} \text {; } \\
\text { sediments be- } \\
\text { low lithified }\end{array}$ & - & - & - \\
\hline
\end{tabular}

Figure 1(A) illustrates a simple break along a sapropel horizon and a rounding caused by rotation, while Figure 1(B) shows a similar effect occurring more frequently along laminae within marls or along slight changes in marl composition. Note that upcore flowage has contorted some of the concave/convex surfaces. Figure 1(C) represents an extreme case where stiff marls and oozes of differing consistencies have been rotated over one another, and Figure 1(D) shows a similar situation to $\mathrm{l}(\mathrm{A})$ but in less lithified and sandy lithologies. Note the rotation of the lower part of the burrow below the sapropel horizon. It is clear from these illustrations that, should the frequency of breakage and rotation along the core become such that the pieces are thinner than they are wide (the plastic liner is $6.6 \mathrm{~cm}$ diameter), the pieces become discs of sediment. This is referred to as core-discing, a process familiar to rig geologists in the drilling industry, and is found when weight on the bit required to core stiff lithologies (especially waxy clays) causes a hammer or bounce effect.

As an example of the problems that core discing can cause, we can refer to the sequence in Core 9, Section 2 of Site 372 (Figure 2[A]). This succession, encountered immediately below the Messinian Evaporite formation on the Menorca Rise, is of extreme importance in assessing the paleoenvironment at the onset of the "salinity crisis," and the shipboard sedimentologists were at great pains to evaluate in detail any sedimentary structures found. Downcore as far as $40 \mathrm{~cm}$ in Section 2, a relatively undisturbed varved interval, was described. Below this a sequence of recurrent features were at first misidentified as cyclic bedding and interpreted as of shallow water origin similar to the varves.
As can be seen from Figure 2(A), core discing is easily identified only below $80 \mathrm{~cm}$, while in the zone between 40 and $80 \mathrm{~cm}$ it is difficult to recognize, although it is suspected that the discing begins at least as high as the base of the varved interval. In fact, careful re-examination of the cores revealed core-discing in the sediments immediately above the evaporite formation also, for example, in Section 372-4-2. The artifact was continually found in subsequent cores downhole from Core 9 . Figure 2(B) illustrates an example in Core 12 where the discing has produced regularly spaced "laminae" on the split core surface within a thoroughly burrowed deep-water pelagic marl. Had these been a primary feature, it is difficult to imagine the burrows not crossing and destroying these structures.

At the subsequent Site 376 one could easily and conclusively demonstrate the effects of core discing (Figure 3). Here it often occurred in relatively homogeneous lithologies (Figure 3[A]) and progressed to the extent that one could remove the individual pieces from the ends of unsplit cores (Figure 3[B]). These had clear evidence of rotation on their upper and lower surfaces in the form of circular striae. As final proof, in Core 9, at Site 376, near vertical irregular sand bodies, intruded presumably by drilling disturbance, were subsequently broken and rotated away from one another by a later stage of core discing (Figure $3[\mathrm{C}]$ and [D]).

\section{Microfaulting in Leg 42A Cores: Microtectonics or Drilling Artifact?}

Microfaulting in semiconsolidated sediments and soft-sediment deformation by slumping should be ubiquitous features of the Mediterranean sea floor as a 


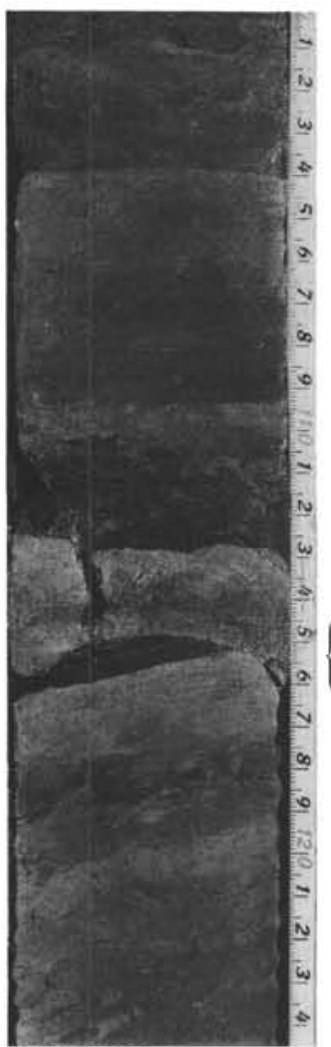

ROTATION

ABOVE

(A) $371.5-4,100.125 \mathrm{~cm}$
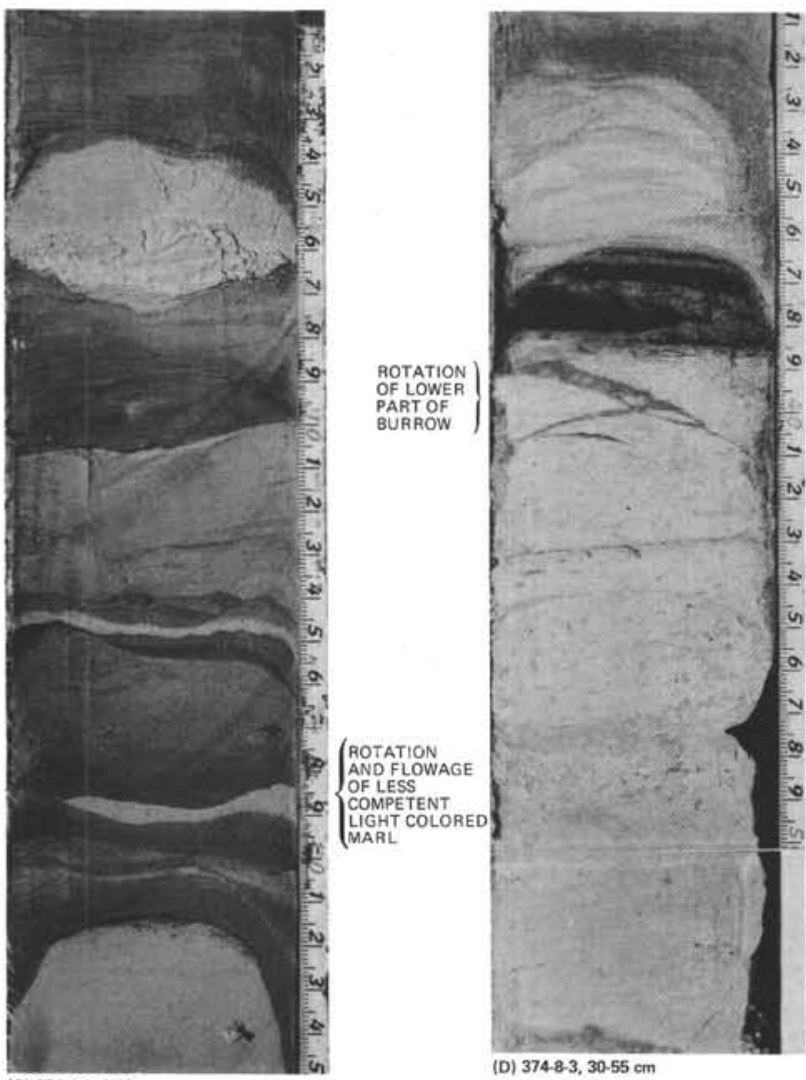

(C) $374.4 .4,0.25 \mathrm{~cm}$

Figure 1. Example of sediment rotation within the core barrel. Leg $42 A$.

B) $371 \cdot 3-3,75-100 \mathrm{~cm}$
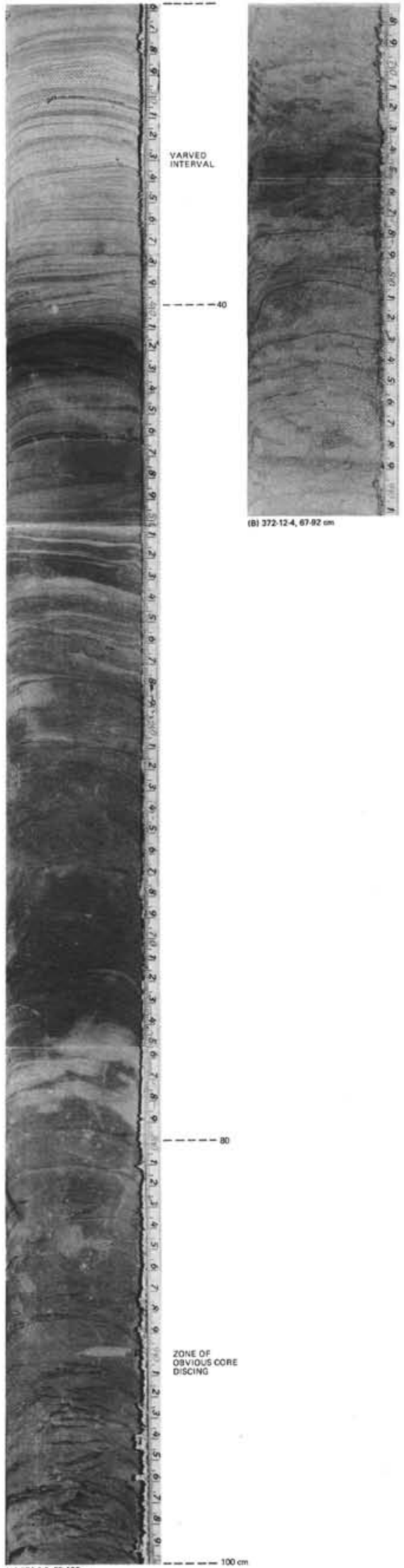

Figure 2. Core discing at Site 372, Leg $42 A$. 
R. B. KIDD

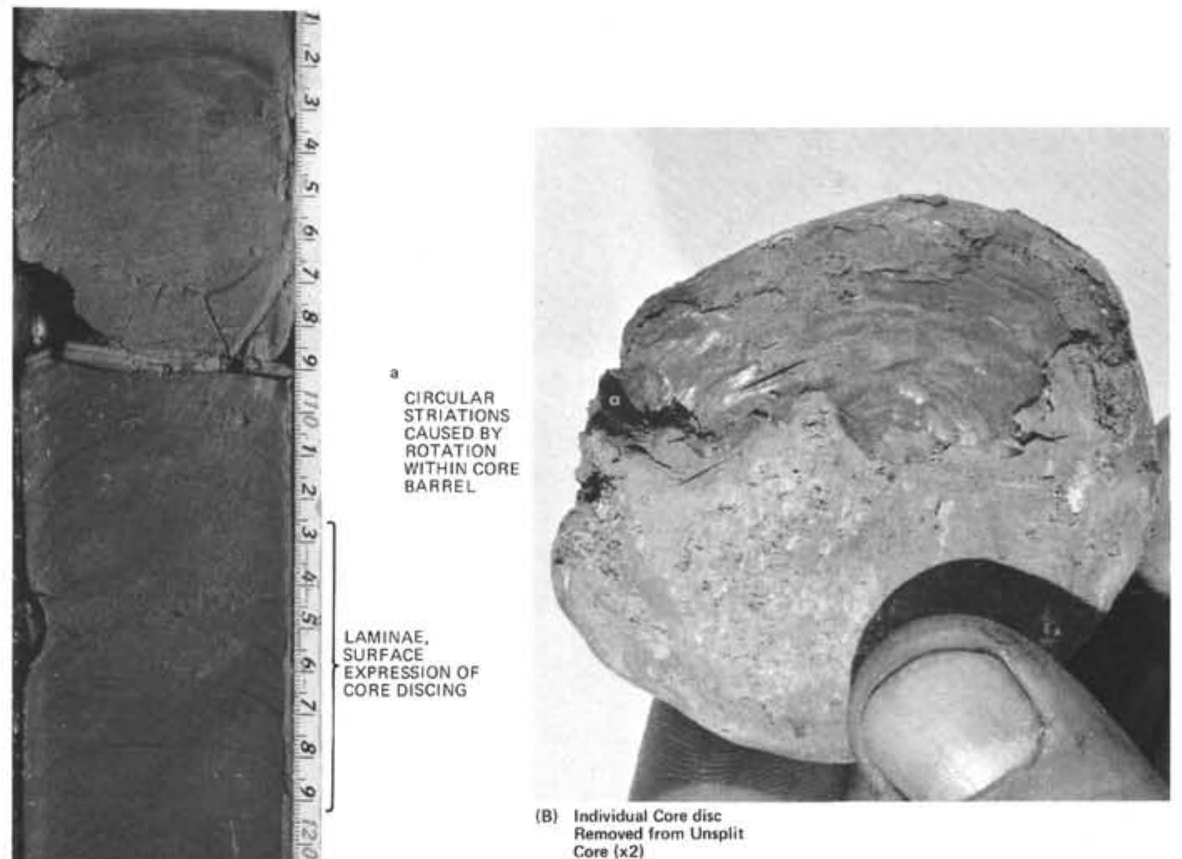
Core $(\times 2)$ rom Unsplit
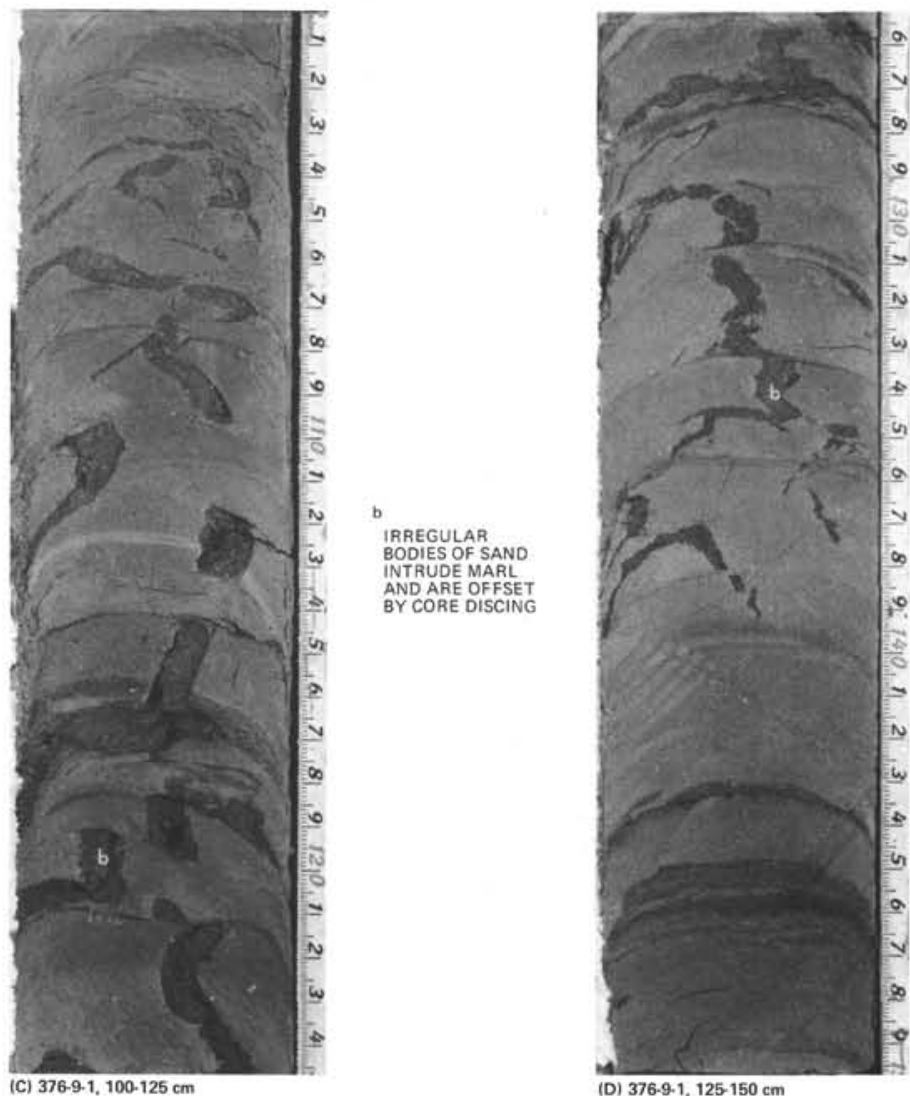

Figure 3. Core discing at Site 376, Leg $42 \mathrm{~A}$. 
result of the region's tectonic instability. Indeed both have been recognized in gravity and box core studies conducted specifically with the aim of recovering sediments undisturbed by the coring process (Kidd, 1975). Slumping is frequently recognized in deep-sea drilling cores from its superimposition of stratigraphies; for example, the Plio-Quaternary sequence of Site 376. However, microfaults noted during visual description of the cores are usually considered artifacts, the result of the coring process. It appears from our experiences on Leg $42 \mathrm{~A}$ that, in areas such as the Mediterranean, more careful investigation for possible original microtectonic features is warranted.

Figure 4 shows a range of microfaults found at Site 374 on the Messina Abyssal Plain. Figures 4(A) and (B) are almost certainly drilling artifacts, since they are continuations of cracks in the split surface of the core resulting from the coring process. On the other hand, Figure 4(D) shows a sapropel horizon burrowed by Chondrites within and butting against indurated dolomite. This is believed to be an example of an originally microfaulted sediment. In Figure 4(C), a dark lamina is offset by a microfault while others above and below are undisturbed. This again may be an original feature.

Even more complex microfaulting was found during Leg $42 \mathrm{~A}$ and was consequently more difficult to interpret. Figure 4(A) illustrates some of these features in the Site 374 sediments. Here a relatively simple displacement of laminae in stiff marls is superceded by a very complex structure which is almost certainly a drilling artifact. Both, consequently, are interpreted as disturbance features. Again, in the Site 374 sediments, a zone of disoriented laminae was recovered (Figure $5[\mathrm{~B}]$ ) which is interpreted as the result of movement between pieces within the core barrel and not of either microtectonics on the seabed or depositional dips (compare Figure 1[A]). Figure $5(\mathrm{C})$ shows a $50-\mathrm{cm}$ section of 376-13-3 which displays not only core discing but also a complex interfingering of the marls and silts themselves. The problem is: is this original soft sediment deformation which has simply been affected by core discing during drilling or is this entirely a drilling artifact where interfingering of the sediment was later overprinted by core discing? The paleoenvironmental interpretation of these sediments ( 376 lithologic subunit $\mathrm{Vb}$ ) suggests an environment of very distal turbidite deposition, and slopes sufficient for soft sediment deformation by slumping would appear unlikely. For this reason we elected to consider the interfingering an artifact. It is nevertheless interesting to speculate what effect an earthquake would have on semiconsolidated sediments of differing competence on the edge of a Mediterranean abyssal plain.

\section{The Effect of Washing During Coring of Soluble Evaporite Rocks}

One sediment recovery problem encountered by Leg $42 \mathrm{~A}$ was relatively new. This was the effect that the use of pumped water during the coring operation has on soluble evaporite rocks. Here the drilling team has the
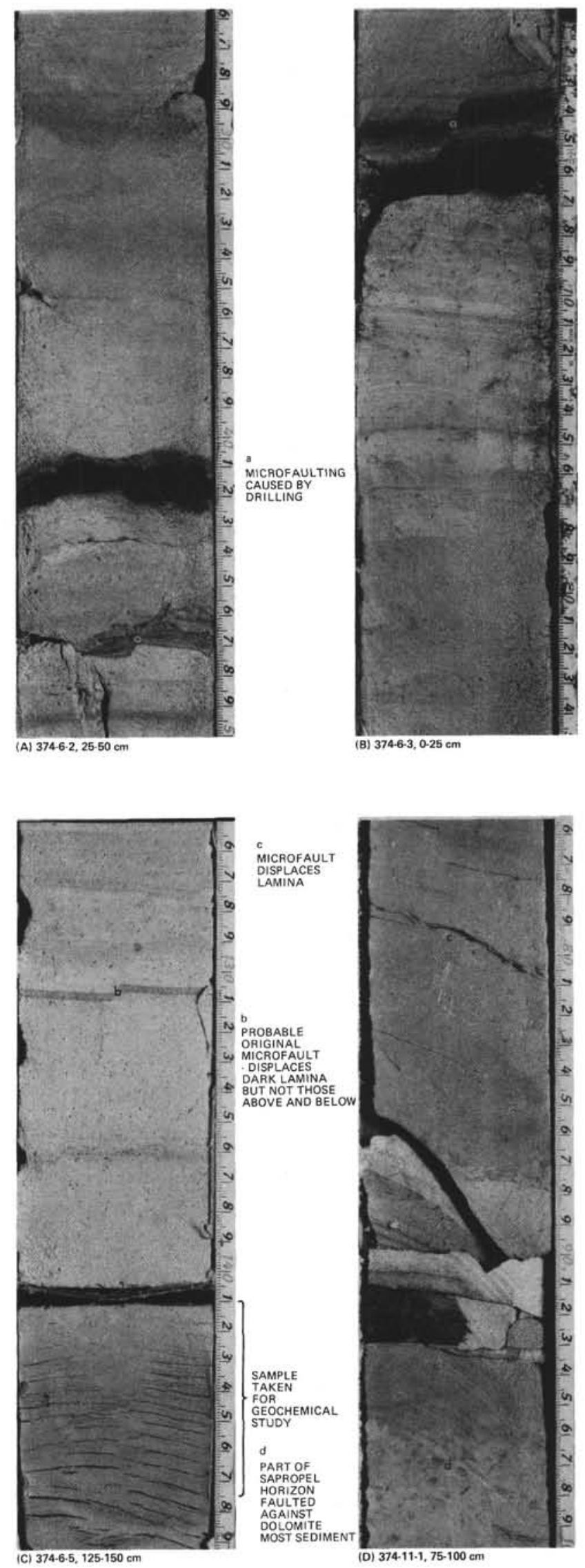

Figure 4. Microfaulting at Site 374, Leg $42 \mathrm{~A}$. 

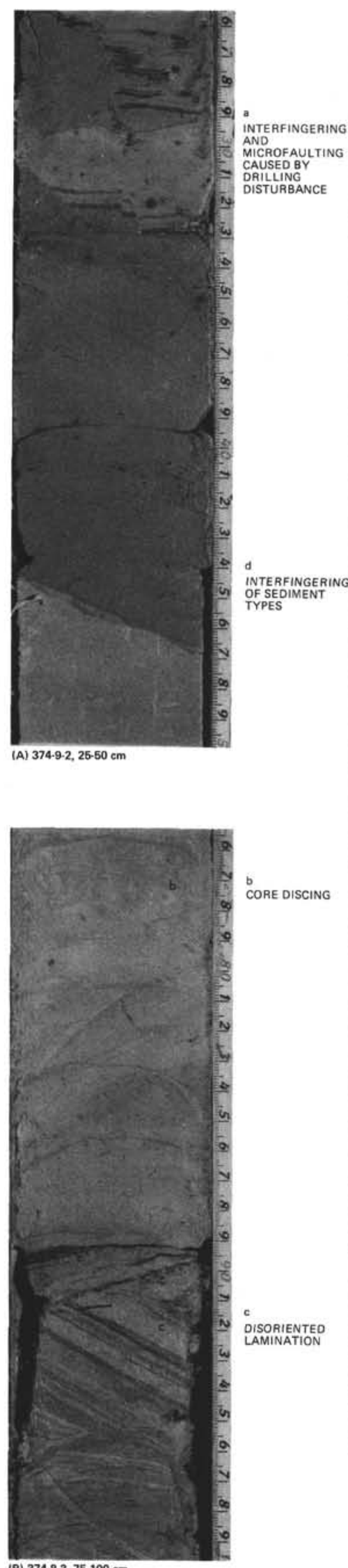

CORE DISCINC

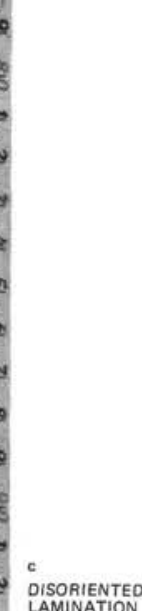

DISORIENTED

.

(2)

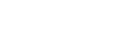

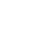

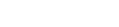

(B) $374-8 \cdot 3,75-100 \mathrm{~cm}$

Figure 5. Complex drilling disturbance features, Leg $42 \mathrm{~A}$.

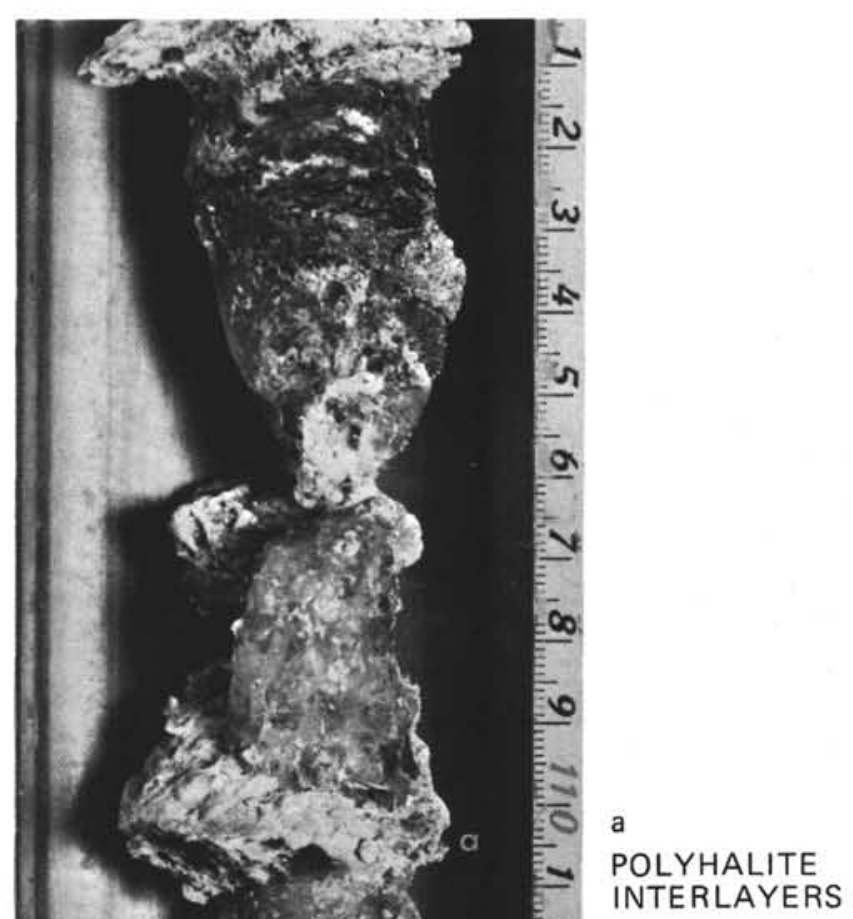

N

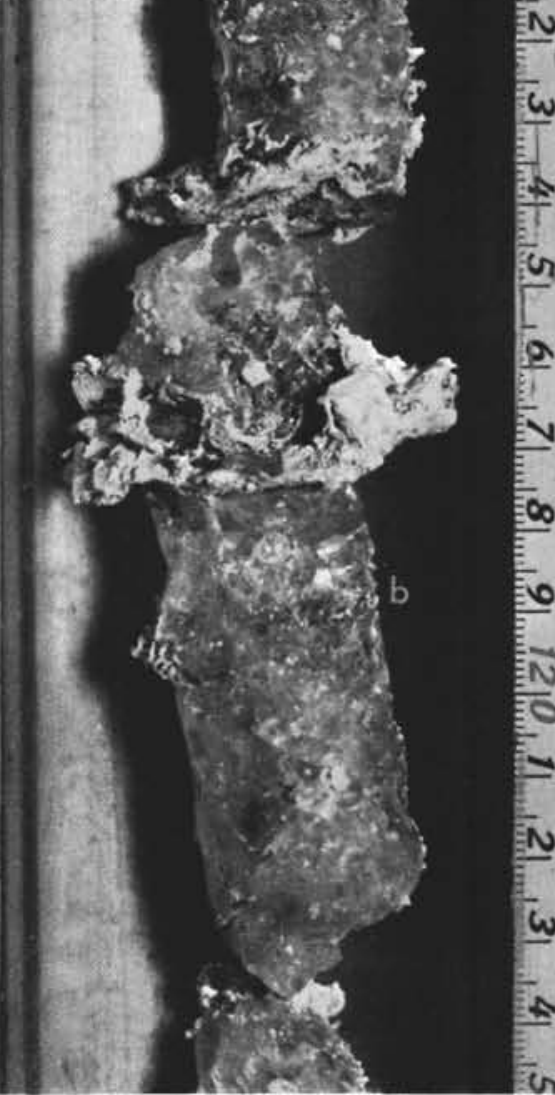

$374-22-1,100-125 \mathrm{~cm}$

Figure 6. Effects of washing on recovery in halite. 
problem of balancing water pumped down the drill string to aid with coring resistant rocks and wash away inhole cuttings against the effect that this operation has on the lithologies being cored. Salt horizons were penetrated at Site 374 . The more soluble potash salts were completely washed away leaving only traces recording their former presence (see Hsü and Kuehn, this volume) whereas halite was successfully recovered. Figure 6 shows an example of our most successful recovery in halite at Site 374 . Here solution has markedly reduced the diameter of the cored material and the less soluble interlayers of clay-size gypsum stand out markedly.

\section{ACKNOWLEDGMENTS}

Larry Lauve of DSDP is thanked for his efforts to make close-up photographs, a number of which appear in this appendix, available to the Leg $42 \mathrm{~A}$ shipboard scientists. Dr. Steve Calvert of I.O.S., Wormley, kindly reviewed the manuscript.

\section{REFERENCES}

Kidd, R. B., 1975. Holocene Sedimentation in the Tyrrhenian Sea: PhD. thesis, University of Southampton.

Kidd, R. B., and Thompson, P., in preparation. Core disturbance: for JOIDES/DSDP Technical Manual being prepared to accompany Initial Reports Volumes. 